A. H. Heald · S. G. Anderson - A. Vyas - K. Siddals • J. Patel · A. P. Yates - D. Bhatnagar - D. Prabhakaran · E. Hughes $\cdot$ A. Rudenski $\cdot$ P. Durrington ·

J. M. Gibson · J. K. Cruickshank

\title{
Marked differences in the IGF system that are associated with migration in comparable populations of Gujaratis living in Sandwell, UK, and Gujarat, India
}

Received: 1 September 2004 / Accepted: 25 November 2004 / Published online: 22 July 2005

(C) Springer-Verlag 2005

\begin{abstract}
Aims/hypotheses: We previously reported independent links between the IGF system and the development of impaired glucose tolerance and cardiovascular risk. This study tests the hypothesis that the lifestyle change which accompanies population migration, with attendant increases in cardiovascular risk, is reflected by changes in the IGF system. Materials and methods: We compared a specific Gujarati community in Sandwell, UK $(n=205)$, with people still resident in the same villages of origin near Navsari, India $(n=246)$. We performed anthropometry and measured fasting plasma insulin, IGF-I, insulin-like growth factor binding protein (IGFBP)-1 and IGFBP-3. Results: Daily calorie intake, BMI and WHR were significantly higher in UK Gujaratis than in Indian
\end{abstract}

\author{
A. H. Heald $(\bowtie) \cdot$ K. Siddals · A. Rudenski · J. M. Gibson \\ Department of Diabetes and Endocrinology, \\ Salford Royal Hospitals University Trust, \\ Hope Hospital, University of Manchester, \\ Stott Lane, Salford, \\ Greater Manchester, M6 8HD, UK \\ e-mail: aheald@fs1.ho.man.ac.uk \\ Tel.: +44-161-7875146 \\ Fax: +44-161-7875989 \\ S. G. Anderson · A. Vyas · J. Patel · J. K. Cruickshank \\ Clinical Epidemiology Group, \\ University of Manchester Medical School, \\ Manchester, UK \\ S. G. Anderson · A. Vyas · A. P. Yates · D. Bhatnagar · \\ P. Durrington - J. K. Cruickshank \\ University Department of Medicine, \\ Manchester Royal Infirmary, \\ Manchester, UK \\ J. Patel $\cdot$ E. Hughes \\ Department of Clinical Biochemistry, \\ Sandwell General Hospital, \\ Birmingham, UK \\ D. Prabhakaran \\ All India Institute of Medical Sciences, \\ New Delhi, India
}

Gujaratis. IGFBP-1 was significantly lower in UK migrants (mean 29.5 [95\% CI 25.9-33.0] vs 56.5 [50.6-62.5] $\mathrm{\mu g} / \mathrm{l}$; $F=48.4, p<0.001$ ). Conversely, fasting insulin, IGFBP-3 and IGF-I were all higher in UK Gujaratis (mean IGF-I $145.9[138.1-153.6] \mathrm{ng} / \mathrm{ml}$ in UK Gujaratis and 100.9 [94.6$107.3] \mathrm{ng} / \mathrm{ml}$ in Navsari Gujaratis; $F=76.6, p<0.001$ ). These differences were still apparent when adjustment was made for BMI by location for IGF-I $(F=57.4, p<0.001)$ and IGFBP-3 ( $F=5.7, p=0.02)$, but were no longer apparent for IGFBP-1 and insulin. At the population level, the decrease in IGFBP-1 for a given increase in insulin was significantly smaller in UK Gujaratis, suggesting greater hepatic insulin resistance in this group. Conclusions/interpretation: Environmental factors have profound effects on circulating IGF system components and on the relationship between IGFBP-1, IGF-I and related metabolic variables. This may have long-term implications for the development of worsening glucose tolerance and cardiovascular disease.

Keywords IGF · IGFBP-1 - IGFBP-3 - Insulin resistance · Lifestyle $\cdot$ Migration

Abbreviations GTT: glucose tolerance test - HOMA-B: homeostasis model assessment pancreatic beta-cell function - HOMA-S: homeostasis model assessment insulin sensitivity - IRMA: immunoradiometric assay · IGFBP: insulin-like growth factor binding protein

\section{Introduction}

Differences in disease rates between migrant and nonmigrant populations may supply important clues to the aetiology and hence the mechanism of disease [1]. For any ethnic group, lifestyle has a profound effect on insulin metabolism and on the incidence of type 2 diabetes and cardiovascular disease [2]. In people of South Asian origin in the UK, glucose intolerance and coronary heart disease are more prevalent than in white Europeans [3-5], but direct measures of factors associated with migration and 
the mechanisms resulting in increased disease rates have rarely been studied in detail.

There is accumulating evidence that the IGF system is closely involved in the progression to impaired glucose tolerance [6], with the combination of low circulating IGFI and low IGF binding protein (IGFBP)-1 at baseline predisposing to impaired glucose handling at the 5-year follow-up. The IGF system has been implicated in the pathogenesis of hypertension [7], atheromatous vascular disease $[8,9]$, cardiomegaly [10], ischaemic disease [11] and cardiac failure $[12,13]$. IGF bioactivity is modulated by a series of specific high-affinity IGFBPs [14]. Of the six IGFBPs fully characterised, IGFBP-1 is considered to be the principal hour-to-hour regulator of circulating IGF activity [14], forming the link between dietary ingestion, glucose metabolism and the IGF axis. We and others have established close links between the IGF system and the development of impaired glucose tolerance, obesity and macrovascular disease [15-18]. In a white European population, we demonstrated that such changes predict the development of worsening glucose tolerance at the 5-year follow-up [6]. Recently, higher circulating IGF-I levels and a high IGF-I : IGFBP-3 ratio have been associated with the development of breast cancer in premenopausal women [19] and prostate cancer in men [20]. These associations reflect the importance of the IGF system in controlling cell growth, metabolism and apoptosis and highlight the need to attain a better understanding of the environmental and genetic factors involved in IGF system regulation.

The IGF system, dietary factors and how these are shared by or differ with ethnic group all appear to contribute to the development of diabetes and macrovascular disease. Our hypothesis was that the lifestyle changes that occur with population migration are mirrored by specific changes in the IGF system, in particular IGF-I and IGFBP-1.

\section{Subjects, materials and methods}

\section{Study sample}

The study design was a direct comparative populationbased community study, between Gujaratis from the same village of origin, one group living in Sandwell UK (first generation migrants) $(n=205)$, and the others still resident around the town of Navsari in Gujarat, India $(n=246)$. Representative random sampling from population-based registers supplemented by the electoral rolls was conducted at each site [21]. Mean ages $(95 \% \mathrm{CI})$ by site and sex are given in Table 1. Response rates were $72 \%$ in Sandwell, UK, and $67 \%$ in Navsari, Gujarat. Of the Sandwell participants, $22 \%$ had migrated to the UK before puberty.

The subjects of the study gave informed consent. Ethical approval for the study was obtained both in Sandwell, UK, and Gujarat, India, from the respective local ethics committees.

\section{Baseline examination}

Participants attended clinic in the fasting state, having fasted from 22.00 hours on the previous evening. The blood samples were taken between 08.00 and 09.00 hours. Venous blood was collected, separated and appropriately stored. Participants without previously diagnosed diabetes on the basis of self-report/health records and a fasting capillary glucose $<7 \mathrm{mmol} / \mathrm{l}$ were asked to complete a GTT [22]. A 75-g equivalent glucose load was administered as a fruit-flavoured drink (Maxijoule; SHS Supplies, UK). Venous blood samples were collected 30 and $120 \mathrm{~min}$ after the glucose challenge [20]. Blood samples were centrifuged and aliquots of plasma or serum were frozen at $-70^{\circ} \mathrm{C}$ until analysis.

Table 1 Unadjusted lifestyle risk factors among Gujarati Indians in Sandwell (UK) compared with contemporaries living in Navsari (India)

\begin{tabular}{|c|c|c|c|c|}
\hline \multirow[t]{2}{*}{ Lifestyle factor } & \multicolumn{2}{|l|}{ Men } & \multicolumn{2}{|l|}{ Women } \\
\hline & Gujarat $(n=128)$ & UK $(n=103)$ & Gujarat $(n=118)$ & UK $(n=102)$ \\
\hline Age (years) & $50.8(14.6)$ & $48.4(12.8)$ & $49.5(14.0)$ & $47.5(11.6)$ \\
\hline Height (m) & $1.64(0.07)$ & $1.68(0.06)$ & $1.52(0.06)$ & $1.53(0.05)$ \\
\hline BMI $\left(\mathrm{kg} / \mathrm{m}^{2}\right)$ & $21.0(3.9)$ & $25.9(3.9)$ & $21.2(4.1)$ & $26.8(5.0)$ \\
\hline WHR & $0.87(0.07)$ & $0.91(0.09)$ & $0.79(0.07)$ & $0.82(0.09)$ \\
\hline Systolic blood pressure & $122(21)$ & $134(20)$ & $111(22)$ & $121(21)$ \\
\hline Diastolic blood pressure & $75(12)$ & $84(11)$ & $69(11)$ & $75(11)$ \\
\hline Total energy intake (kcal/day) ${ }^{\mathrm{a}}$ & $1,362(1,139-1,503)$ & $2,323(1,914-2,788)$ & $1,178(929-1,367)$ & $1,731(1,421-1,985)$ \\
\hline IGF-I (ng/l) & $114.6(57.4)$ & $155.0(47.5)$ & $89.7(37.1)$ & $136.0(50.9)$ \\
\hline IGFBP-1 ${ }^{\mathrm{a}}(\mu \mathrm{g} / \mathrm{l})$ & $59.3(29.4-68.4)$ & $26.6(11.9-33.5)$ & $54.2(27.0-69.1)$ & $32.3(17.2-42.3)$ \\
\hline IGFBP-3 (mg/l) & $3.63(0.83)$ & $3.69(0.79)$ & $3.63(0.97)$ & $3.91(0.94)$ \\
\hline Fasting plasma glucose $(\mathrm{mmol} / \mathrm{l})$ & $5.8(2.4)$ & $5.6(1.9)$ & $5.4(1.7)$ & $5.4(1.8)$ \\
\hline Fasting insulin $(\mathrm{pmol} / \mathrm{l})^{\mathrm{a}}$ & $10.3(5.0-12.6)$ & $12.6(7.7-15.3)$ & $9.7(6.5-7.8)$ & $12.5(11.8-15.1)$ \\
\hline HOMA-S $\%^{a}$ & $106.8(50.0-131.3)$ & $70.0(41.3-85.4)$ & $91.4(54.6-100.9)$ & $74.9(44.0-84.0)$ \\
\hline HOMA-B $\%{ }^{a}$ & $105.2(61.0-126.0)$ & $127.0(86.4-158.3)$ & $112.7(84.7-135.2)$ & $139.3(99.2-155.5)$ \\
\hline
\end{tabular}

Values are arithmetic mean (SD) except ${ }^{\text {a }}$ median with interquartile range (25th and 75 th percentiles) for skewed data 
Table 2 Age-adjusted lifestyle risk factors among Gujarati Indians in Sandwell (UK) compared with contemporaries living in Navsari (India)

\begin{tabular}{|c|c|c|c|c|c|c|}
\hline \multirow[t]{2}{*}{ Lifestyle factor } & \multicolumn{2}{|l|}{ Men } & \multirow{2}{*}{$\begin{array}{l}p \text { value for } \\
\text { comparison } \\
\text { by site }\end{array}$} & \multicolumn{2}{|l|}{ Women } & \multirow{2}{*}{$\begin{array}{l}p \text { value for } \\
\text { comparison } \\
\text { by site }\end{array}$} \\
\hline & Gujarat $(n=128)$ & UK $(n=103)$ & & Gujarat $(n=118)$ & UK $(n=102)$ & \\
\hline Height (m) & $1.65(0.005)$ & $1.67(0.005)$ & $\begin{aligned} F & =12.1 ; \\
p & =0.0006\end{aligned}$ & $1.52(0.005)$ & $1.53(0.005)$ & $\begin{array}{l}F=1.6 \\
p=0.21\end{array}$ \\
\hline BMI $\left(\mathrm{kg} / \mathrm{m}^{2}\right)$ & $21.0(0.36)$ & $25.9(0.38)$ & $\begin{array}{l}F=98.7 \\
p<0.0001\end{array}$ & $21.2(0.33)$ & $26.9(0.38)$ & $\begin{array}{l}F=120.0 \\
p<0.0001\end{array}$ \\
\hline WHR & $0.87(0.007)$ & $0.92(0.007)$ & $\begin{array}{l}F=23.6 ; \\
p<0.0001\end{array}$ & $0.79(0.006)$ & $0.82(0.007)$ & $\begin{aligned} F & =10.7 \\
p & =0.00012\end{aligned}$ \\
\hline $\begin{array}{l}\text { Systolic blood } \\
\text { pressure }(\mathrm{mmHg})\end{array}$ & $121(1.64)$ & $135(1.76)$ & $\begin{array}{l}F=29.8 ; \\
p<0.0001\end{array}$ & $111(1.50)$ & $122(1.75)$ & $\begin{array}{l}F=25.9 \\
p<0.0001\end{array}$ \\
\hline $\begin{array}{l}\text { Diastolic blood } \\
\text { pressure }(\mathrm{mmHg})\end{array}$ & $75(0.93)$ & $84(0.99)$ & $\begin{array}{l}F=37.6 ; \\
p<0.0001\end{array}$ & $69(0.85)$ & $75(0.99)$ & $\begin{array}{l}F=29.9 \\
p<0.0001\end{array}$ \\
\hline $\begin{array}{l}\text { Total energy intake } \\
\text { (kcal/day) }\end{array}$ & $1,366(102.8)$ & $2,183(68.3)$ & $\begin{array}{l}F=43.4 ; \\
p<0.0001\end{array}$ & $1,195(92.7)$ & $1,716(78.4)$ & $\begin{array}{l}F=18.5 \\
p<0.0001\end{array}$ \\
\hline
\end{tabular}

Values are arithmetic means (SE)

Adjusted means are calculated from linear regression models; adjusted medians are calculated from quantile regression models

${ }^{a}$ Age-adjusted medians (SE) for skewed data

Blood pressure was measured while subjects were seated, using a validated semiautomatic monitor (Omron HEM-705CP; Omron Healthcare, Bannockburn, IL, USA) after participants had completed a questionnaire (at both sites). Fieldworker procedures were rigorously standardised, a process repeated within teams every month, with regular cross-site visits every 4 months. Standardised measures of anthropometry such as BMI and WHR were taken by trained fieldworkers, after subjects had responded to a detailed lifestyle questionnaire [1].

A 4-day food diary was supplied to each participant, with a request to complete it and include one weekend day in the time-span reported. Diaries were calibrated with 24-h food recalls.

Table 3 Metabolic factors (age-adjusted) among Gujarati Indians living in Sandwell (UK) compared with contemporaries living in Navsari (India)

\begin{tabular}{|c|c|c|c|c|c|c|}
\hline \multirow[t]{2}{*}{ Metabolic factors (fasting) } & \multicolumn{3}{|l|}{ Men } & \multicolumn{3}{|l|}{ Women } \\
\hline & Gujarat & UK & $\begin{array}{l}p \text { value for } \\
\text { comparison } \\
\text { by site }\end{array}$ & Gujarat & UK & $\begin{array}{l}p \text { value for } \\
\text { comparison } \\
\text { by site }\end{array}$ \\
\hline IGF-I (ng/l) & $113.6(5.2)$ & $154.6(5.9)$ & $\begin{array}{l}F=27.1 ; \\
p<0.0001\end{array}$ & $92.0(3.53)$ & $132.8(4.65)$ & $\begin{array}{l}F=48.6 ; \\
p<0.0001\end{array}$ \\
\hline IGFBP-1 $^{\mathrm{a}}(\mu \mathrm{g} / \mathrm{l})$ & $45.9(3.4)$ & $18.7(3.9)$ & $\begin{array}{l}F=28.0 ; \\
p<0.0001\end{array}$ & $41.9(3.59)$ & $28.1(4.44)$ & $\begin{array}{l}F=5.8 \\
p=0.017\end{array}$ \\
\hline IGFBP-3 (mg/l) & $3.63(0.08)$ & $3.67(0.10)$ & $\begin{array}{c}F=0.09 \\
p=0.77\end{array}$ & $3.64(0.079)$ & $3.92(0.12)$ & $\begin{array}{l}F=3.9 \\
p=0.049\end{array}$ \\
\hline Fasting plasma glucose (mmol/l) & $5.4(0.1)$ & $5.2(0.1)$ & $\begin{array}{l}F=1.5 ; \\
p=0.22\end{array}$ & $5.3(0.1)$ & $5.2(0.1)$ & $\begin{array}{l}F=0.3 ; \\
p=0.60\end{array}$ \\
\hline Fasting insulin ${ }^{\mathrm{a}}(\mathrm{pmol} / \mathrm{l})$ & $8.2(0.6)$ & $10.2(0.6)$ & $\begin{array}{l}F=4.9 ; \\
p=0.028\end{array}$ & $9.0(0.4)$ & $9.3(0.4)$ & $\begin{array}{l}F=0.2: \\
p=0.66\end{array}$ \\
\hline HOMA-S ${ }^{\mathrm{a}}(\%)$ & $81.8(5.15)$ & $68.1(5.24)$ & $\begin{array}{l}F=3.4 \\
p=0.065\end{array}$ & $73.2(3.19)$ & $71.4(3.44)$ & $\begin{array}{l}F=0.1 ; \\
p=0.72\end{array}$ \\
\hline HOMA-B $^{\mathrm{a}}(\%)$ & $105.3(6.60)$ & $127.4(6.80)$ & $F=5.4 ; p=0.021$ & $112.6(5.85)$ & $123.2(6.32)$ & $\begin{array}{c}F=1.52 \\
p=0.21\end{array}$ \\
\hline
\end{tabular}

Values are arithmetic means (SE)

Comparison is by linear regression by site for each sex

${ }^{a}$ Adjusted medians (SE) were predicted from quantile regression models, adjusted for covariates (age)

Homeostasis model; HOMA B refers to beta-cell function and HOMA S to insulin sensitivity 
Assays

IGFBP-1 levels were determined with a previously reported antibody based assay [23] with a detection limit $3 \mu \mathrm{g} / \mathrm{l}$ and within- and between-assay CVs of $<8 \%$. IGF-I was measured using the DPC Immulite Autoanalyser (DPC, Los Angeles, CA, USA). IGFBP-3 was measured using the DSL (DSL, Webster, TX, USA) immunoradiometric assay (IRMA).

Plasma glucose was determined in the Department of Biochemistry, Sandwell Hospital, and the Mankodi Laboratory, Navsari. Both sites used glucose oxidase autoanalyser methods, the Vitros 950 (Vitros, Raritan, NJ, USA) in Britain, and Technicon RA-50 (Bayer Diagnostics, Gujarat, India). Tight quality control was maintained by the use of the same control specimens at both laboratories. All other assays were carried out in Manchester, UK. Plasma and serum aliquots were transported from India to the UK by air, using dry ice (dry shippers; BDHMerck UK). Fasting lipids were measured on a Cobas Mira autoanalyser. Serum NEFA were analysed with an enzymatic colorimetric method (Wako chemicals, Neuss, Germany). Serum insulin was measured with a modified in-house assay using charcoal extraction (A. P. Yates,
Clinical Chemistry) [24] with $30 \%$ cross-reactivity for proinsulin.

Homeostasis model assessment insulin sensitivity (HOMA-S) and pancreatic beta cell function (HOMA-B) were calculated from fasting insulin and glucose concentrations. This was done using an iterative computer program using a non-linear model for glucose and insulin homeostasis $[25,26]$.

Statistical analysis

The data (individuals with known type 2 diabetes were excluded) were analysed using the statistical package Intercooled Stata version 8.0 (Stata, College Station, TX, USA). Anthropometric and metabolic data are expressed as arithmetic means with SD when normally distributed. Anthropometric and metabolic data are expressed as median with interquartile range ( 25 and $75 \%$ percentiles), or median (SE) when non-normally distributed. Adjusted medians and their SEs were predicted from quantile regression models, adjusted for specified covariates. Comparison of means was by $t$-test or ANOVA. Logarithmic transformation was performed on non-normally distributed variables. a

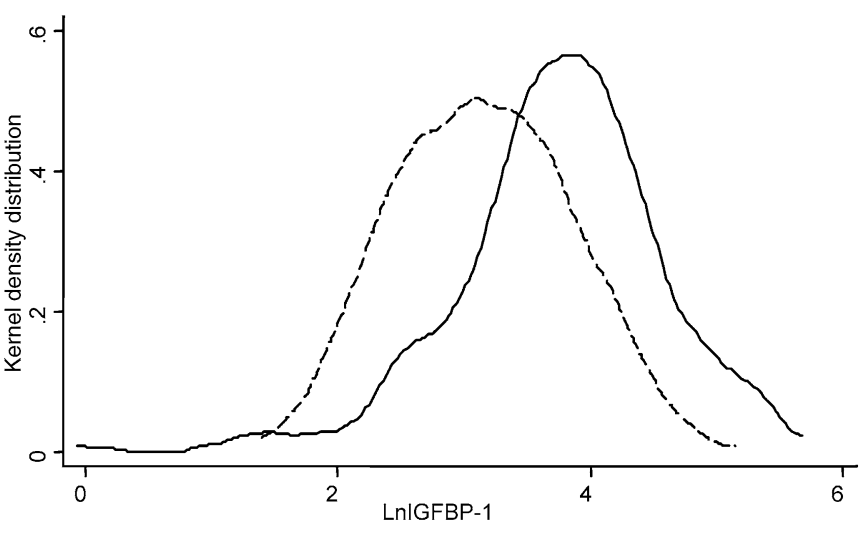

C

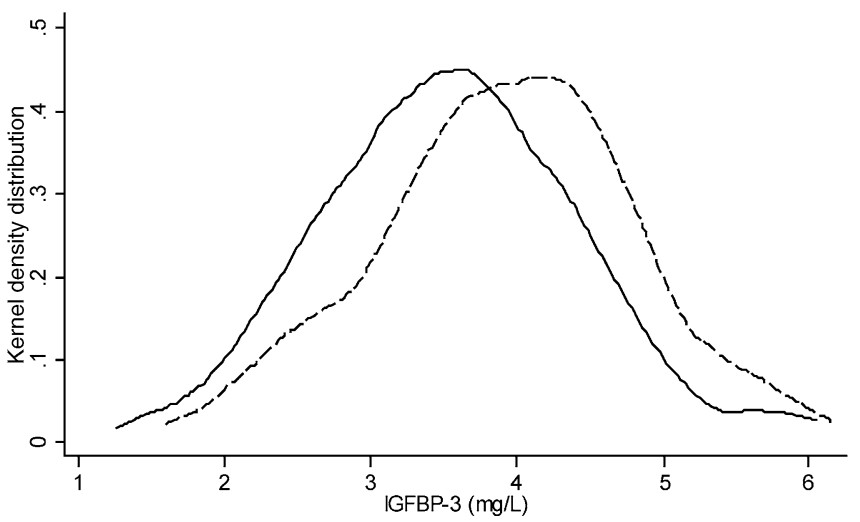

b

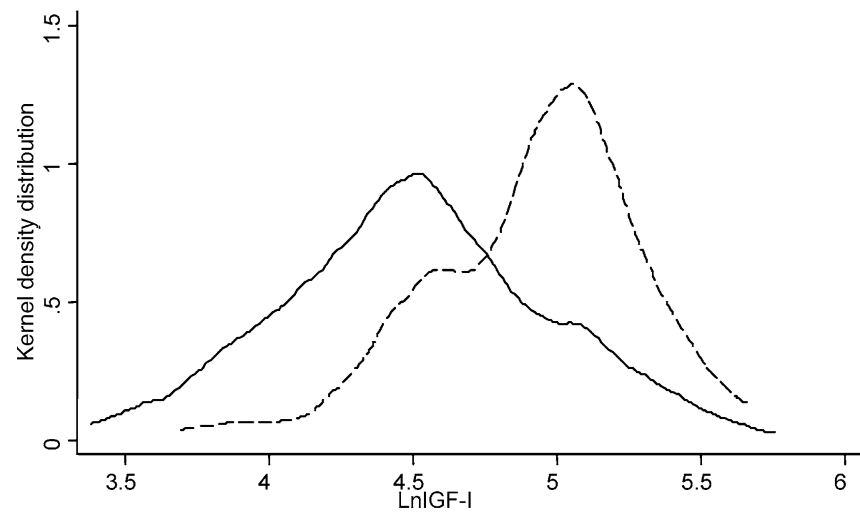

d

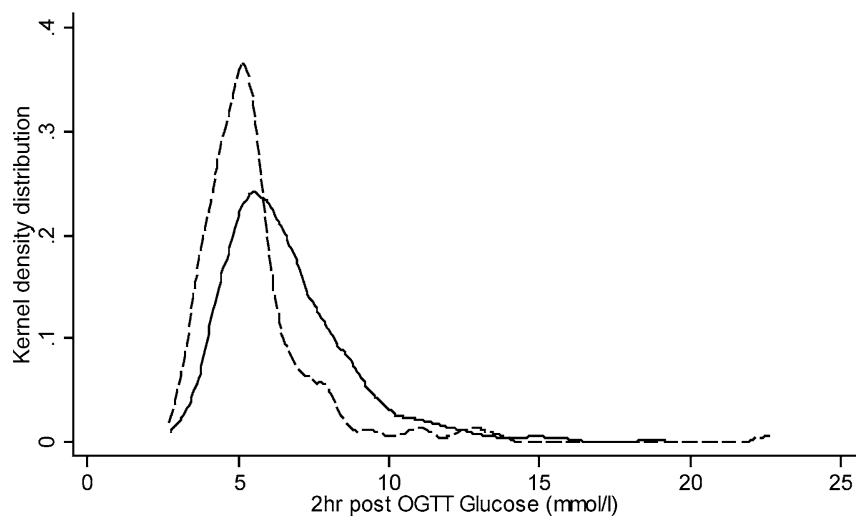

Fig. 1 Distribution of a lnIGFBP-1, b lnIGF-I, c IGFBP-3, and d 2-h glucose by migrant status. Broken line, Sandwell group; unbroken line, Navsari group 
For univariate correlation between continuous variables, Spearman coefficients were used, with partial coefficients for multivariate correlation. A $p$-value of $<0.05$ was considered significant. The standardised beta coefficients presented allow direct comparison (along a scale of $0-1$ ) of the strength of each association between ethnic groups as well as for the total sample. As not all subjects had all measurements owing to missing samples, numbers varied between analyses. Similarly, patients with known diabetes were excluded from all analyses.

Kernel density estimation in Stata was used to plot the frequency distributions for IGF-I, IGFBP-1 and IGFBP-3 by site for all subjects. Kernel density estimation is an approximate probability function $(f)$ of a random variable (x) [27], so that the plots approximate a distribution of all the data points, weighted for their frequency.

\section{Results}

\section{General characteristics}

As shown in Tables 1 and 2, men and women at the two locations had similar age distributions. Mean ages were similar: 50.1 (48.5-51.7) (mean, SD) years in Sandwell, and 48.9 (47.4-50.4) years in Navsari. Unadjusted descriptive and metabolic data are shown in Table 1, while descriptive data adjusted for age are presented in Table 2.

Men in Sandwell were taller than contemporaries in Gujarat, but female height was similar at the two sites. BMI and WHR were substantially higher in men and women in Sandwell than in people still resident in Gujarat, as were systolic and diastolic blood pressures. Rates of total type 2 diabetes (known and new on the basis of oral glucose tolerance testing, WHO 1999 criteria) were similar between the sites for men (Navsari 17.1\% [10.8-23.4], Sandwell $19.2 \%$ [12.9-25.4]) but lower for women in Navsari (10.3\% [4.8-15.9]) than in Sandwell (17.1\% [10.3-23.9]).

Table 4 Spearman correlations $(\rho)$ for IGFBP-1 vs established cardiovascular risk factors for each site

\begin{tabular}{lccccl}
\hline & Gujarat & & UK \\
\cline { 2 - 3 } \cline { 5 - 6 } & $\rho$ & $p$ value & & \multicolumn{2}{c}{$p$ value } \\
\hline Insulin 0 h & -0.48 & 0.0 & -0.33 & 0.0 \\
Insulin 2 h & -0.28 & 0.0002 & -0.24 & 0.006 \\
Glucose 0 h & -0.22 & 0.001 & -0.09 & 0.26 \\
Glucose 2 h & -0.12 & 0.074 & -0.16 & 0.064 \\
HOMA-S & 0.48 & 0.0 & 0.31 & 0.0002 \\
HOMA-B & -0.29 & 0.0 & -0.22 & 0.0073 \\
Triglycerides & -0.36 & 0.0 & -0.13 & 0.10 \\
NEFA & 0.003 & 0.96 & -0.14 & 0.085 \\
BMI & -0.66 & 0.0 & -0.50 & 0.0 \\
WHR & -0.28 & 0.0 & -0.24 & 0.0028 \\
Systolic blood pressure & -0.21 & 0.0018 & -0.09 & 0.26 \\
Diastolic blood pressure & -0.37 & 0.0 & -0.19 & 0.020 \\
\hline
\end{tabular}

Data for fasting glucose by sex and by site are given in Table 1 (unadjusted) and Table 3 (adjusted for age).

Differences in IGFBP, IGF-I, insulin and 2-h glucose levels by location

Fasting IGFBP-1 (age-adjusted) (Fig. 1a, Table 3) was significantly lower in Sandwell Gujarati men and women than in Navsari Gujaratis. Conversely, IGF-I was higher in UK Gujarati men and women (Fig. 1b), as was IGFBP-3 (Fig. 1c). Fasting insulin was higher in Sandwell Gujaratis (Table 3). Two-hour glucose was higher in Navsari (Fig. 1d). Between-site differences in IGF-I $(F=57.4$, $p<0.0001)$, IGFBP-3 $(F=5.7, p=0.021)$ and 2-h glucose $(F=38.9, p<0.0001)$ were still apparent after adjustment for BMI. However, after such adjustment, differences by site for IGFBP-1 and fasting insulin were no longer significant. The cross-site differences persisted for IGF-I and IGFBP-1 but not for IGFBP-3 when adjustment was made for total calorie intake.

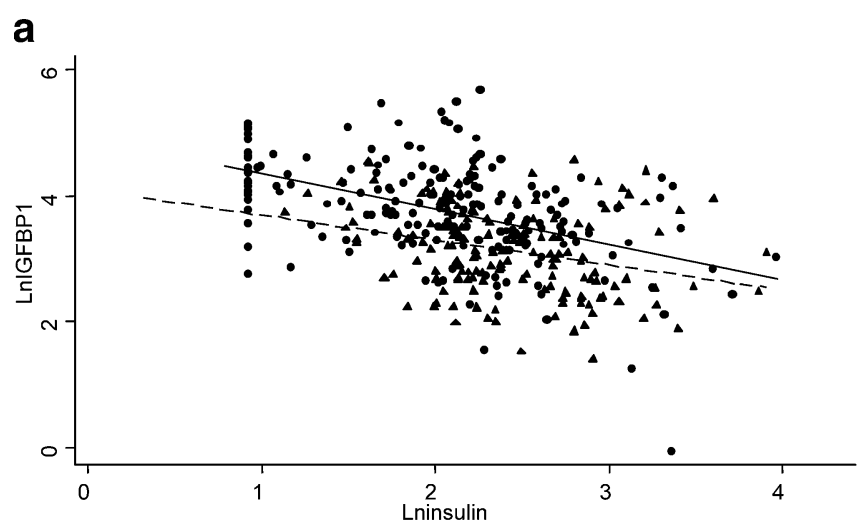

b

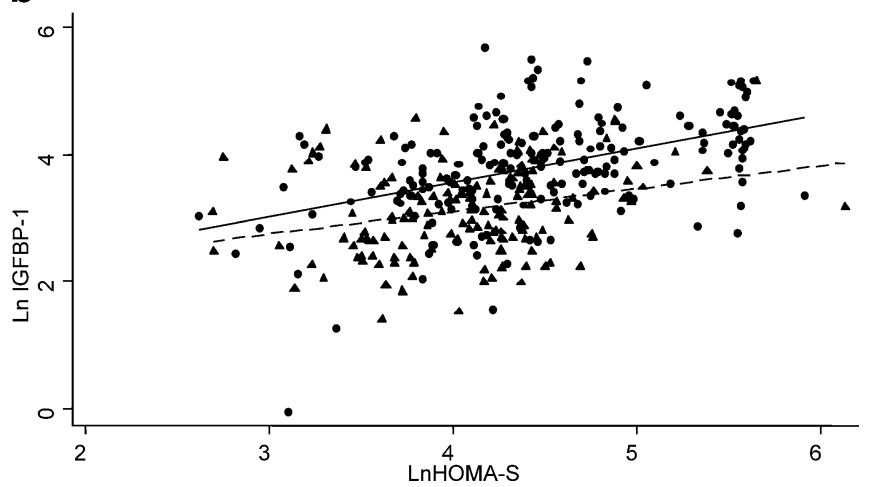

Fig. 2 a Plot of log IGFBP-1 vs log fasting insulin by migrant status. Closed circles, Navsari subjects; closed triangles, Sandwell subjects; unbroken line, fitted values Navsari; broken line, fitted values Sandwell. The vertical line of points at just less than log insulin $=1$ corresponds to the lower limit of sensitivity of the insulin assay. b Plot of log IGFBP-1 versus log HOMA-S by migrant status. Key (as for panel a) 
Fig. 3 a Circulating NEFA levels at 0,30 and $120 \mathrm{~min}$ after 75 -g oral glucose load (for men and women separately). Comparison is by ANOVA for $2-\mathrm{h}$ NEFA. b Circulating intact insulin levels at 0,30 and $120 \mathrm{~min}$ after 75 -g oral glucose load (for men and women separately). Comparison is by ANOVA for 2-h insulin a

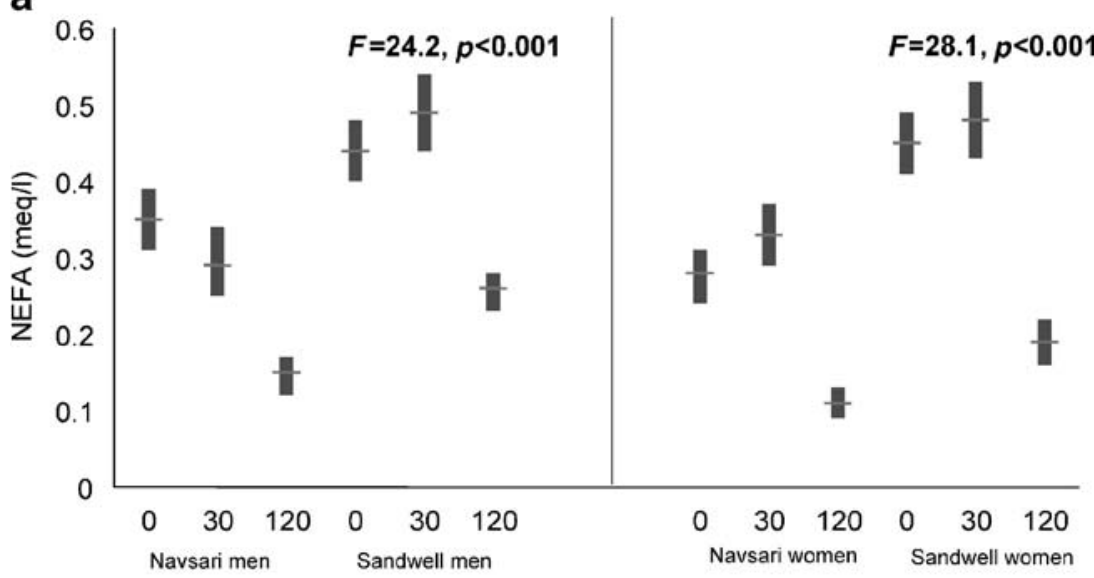

b

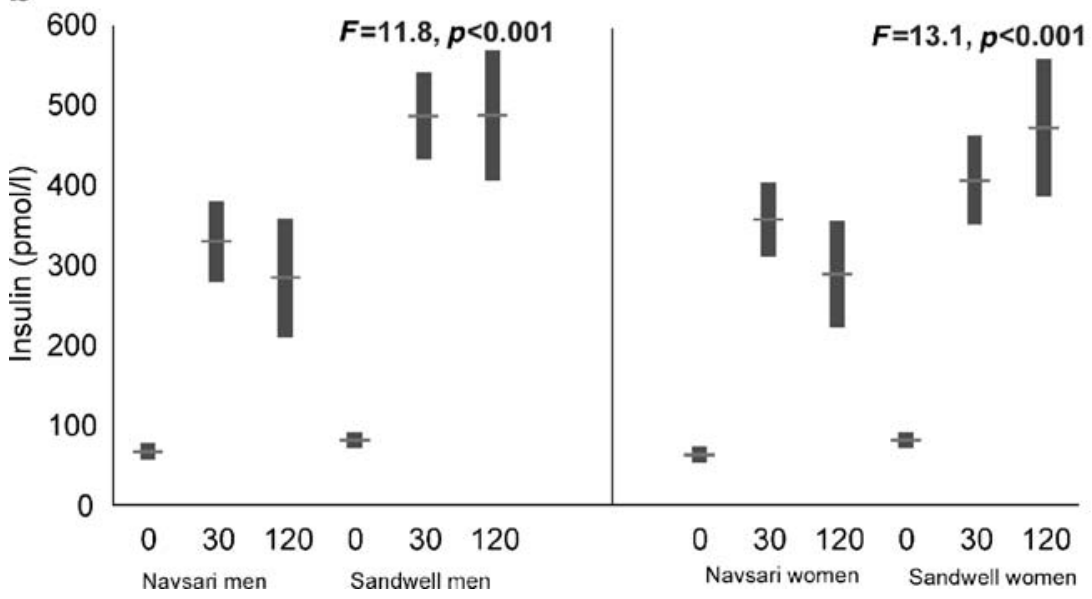

Relationship between IGFBP-1 and insulin

As expected, there was a highly significant inverse association between IGFBP-1 and fasting insulin concentrations (Table 4, Fig. 2a). The decrease in the mainly hepatically synthesised IGFBP-1 for each unit increase in insulin (its principal negative regulator), was smaller in Sandwell Gujaratis $(\log$ IGFBP- $1=-0.40 \times \log$ insulin +4.1$)$ than in Navsari Gujaratis (log IGFBP- $1=-0.55 \times \log$ insulin+4.9, $t=3.2, p=0.0083$ for difference in the regression coefficients). Similarly, there was a difference between the sites for the relation between IGFBP-1 and HOMA-S; for Navsari log IGFBP-1=1.44+0.53 log (HOMA-S), and for Sandwell $\log$ IGFBP-1=1.67+0.34 $\log$ (HOMA-S) (Fig. 2b) $(t=3.4, p=0.0092$ for difference in regression coefficients). Thus the association between IGFBP-1 and HOMA-S was less strong in Sandwell than in Navsari.

The relation between HOMA-B and IGFBP-1 was similar between the two groups (Sandwell Gujaratis, log IGFBP-1 $=4.8-0.35 \log$ [HOMA-B]; Navsari Gujaratis log IGFBP-1 $=5.6-0.39 \log [$ HOMA-B], $p$ NS for difference in regression coefficients). However, for any level of HOMAB, IGFBP-1 was significantly higher in Navsari than in Sandwell.
Suppression of NEFA after a glucose challenge was poorer in the Sandwell group than in the Navsari group, both in men $(F=24.2, p<0.001)$ and in women $(F=28.1$, $p<0.0001)$ for comparison of 2-h NEFA by site. This was despite a greater rise in insulin (men, $F=11.8, p<0.0001$; women, $F=13.1, p<0.0001$, for comparison of 2-h insulin by site), in accordance with the greater insulin resistance observed in Sandwell Gujaratis (Fig. 3a,b). Comparison was made by ANOVA. Two-hour NEFA and 2-h insulin were both normally distributed.

Relationship of IGFBP-1 to established cardiovascular risk factors

As seen in Table 4, IGFBP-1 at both sites correlated negatively with BMI, WHR, diastolic blood pressure, serum triglycerides, fasting insulin and 2-h insulin. For Navsari only, IGFBP-1 correlated negatively with systolic blood pressure.

The relation of IGFBP-1 with all these factors was strongest in Navsari. 

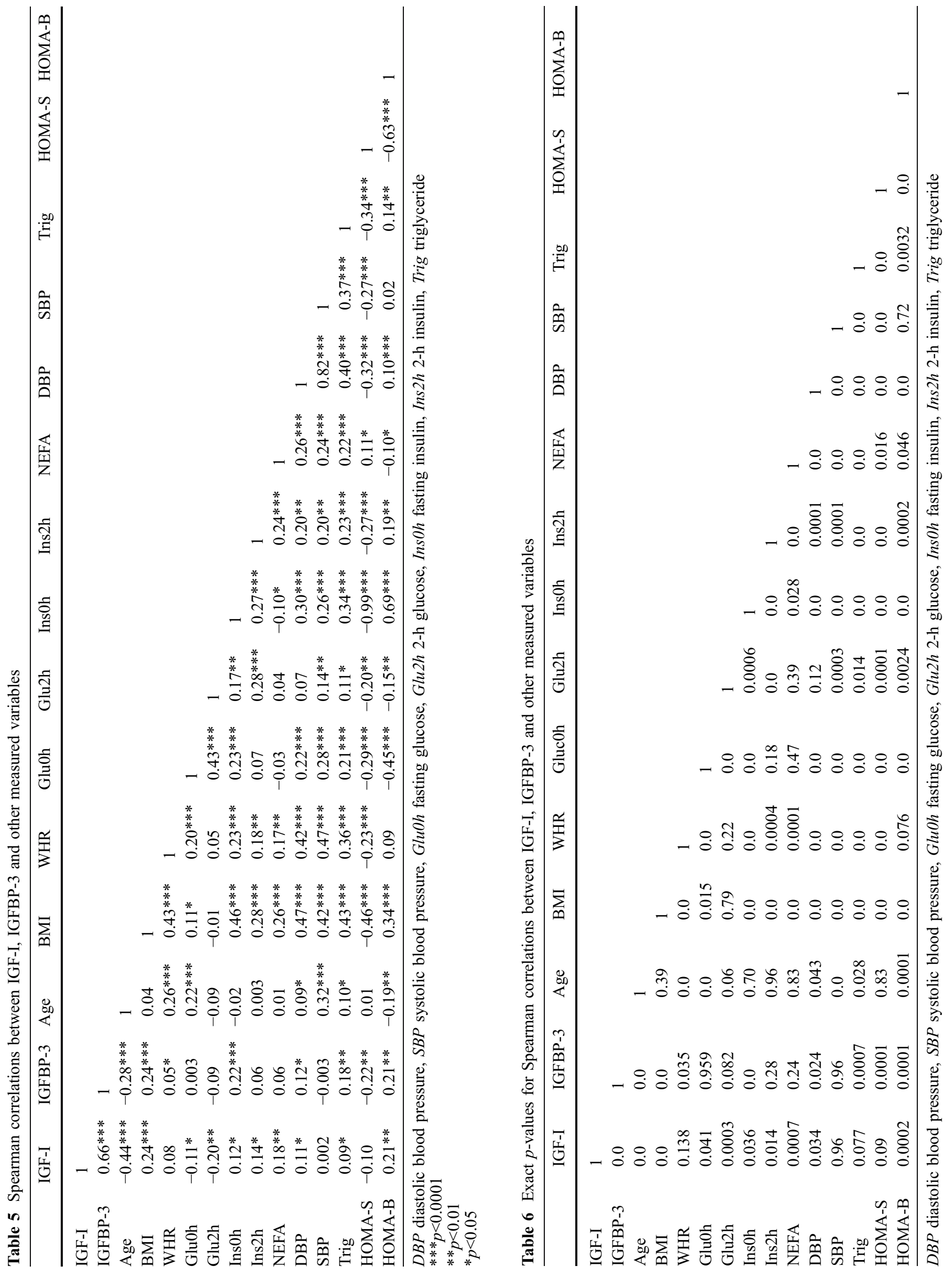
Relation between IGF-I and IGFBP-3

and other measured variables

Tables 5 and 6 show these relations. As anticipated from other studies, there was a negative relation between both IGF-I and IGFBP-3, and increasing age. Elevated BMI was associated with both higher IGF-I and higher IGFBP-3. IGF-I was negatively associated with fasting and 2-h glucose, suggesting a direct link between lower circulating IGF-I and dysregulation of post-prandial glucose, as previously reported in a prospective cohort study [6]. Increasing IGFBP-3 was related to both higher IGF-I and higher fasting insulin, in keeping with the in vitro finding that IGF-I and insulin increase the abundance of IGFBP-3 mRNA in hepatocytes [28]. HOMA-S was associated negatively with circulating IGFBP-3 and HOMA-B was associated positively with both circulating IGF-I and IGFBP-3.

\section{Multiple regression analysis}

The size of the standardised $\beta$ coefficients allows quantitative comparison of the contribution of variables to the relations within the models that follow.

Given the association between IGFBP-1 and glucose level found previously, both cross-sectionally [15] and prospectively [6], the relation between IGFBP-1 glucose and other metabolic variables was examined using a regression model. Forward stepwise linear regression analyses in a model that also included sex, height and log total energy intake showed that, for Navsaris, IGFBP-1 was positively associated with fasting glucose $(\beta=0.32$, $p=0.003)$. This was independent of BMI $(\beta=-0.58$, $p<0.001)$, fasting insulin $(\beta=-0.64, p<0.001))$, IGF-I $(\beta=$ $-0.31, p=0.005)$ and age $(\beta=0.32, p<0.001)$ The model accounted for $72 \%$ of the variation in IGFBP-1. The significance of fasting glucose in the model for Navsaris persists if all significant variables are entered at one time.

A similar model, when applied to Sandwell, accounted for $41 \%$ of the variation in IGFBP-1. For this group, IGFBP-1 was independently and negatively associated with increasing BMI $(\beta=-0.53, p<0.001)$ and IGF-I $(\beta=$ $-0.25, p=0.005)$, independently of the other parameters cited above. There was no independent association of IGFBP-1 with fasting glucose in this model.

\section{Discussion}

In this cross-sectional study of two Gujarati populations from the same sites of origin, we found marked differences in levels of circulating IGF-I, IGFBP-3 and IGFBP-1 depending on whether people had migrated to the UK or remained in Gujarat, India. The significant cross-site differences in individuals from the same extended families suggest that environmental exposure and lifestyle factors profoundly influence IGF-I bioavailability. We hypothesise that such differences in IGF-I bioavailability may account for some of the differences in disease prevalence between non-migrants and individuals who moved from Gujarat to the UK.

The higher circulating IGF-I and IGFBP-3 in Sandwell is compatible with increased hepatic synthesis of IGF-I and IGFBP-3 in relation to this group's greater total energy intake. It is well established that increased total energy intake results in higher levels of IGF-I [29]. The lower IGFBP-1 in Sandwell Gujaratis is in keeping with lower insulin sensitivity (HOMA-S; Table 2), as we have described previously in other ethnic groups [15]. HOMA-S is low in the Sandwell Gujaratis. However, in our previous paper [15], which described HOMA-S in South Asians of Pakistani origin living in the UK, HOMA-S in individuals of normal glucose tolerance status was similar to the values reported here.

In the multiple regression analysis, we found an independent association of higher circulating IGFBP-1 with higher fasting glucose in Navsari, suggesting that IGFBP-1 rises in response to higher levels of glucose. This relation was lost in multiple regression analysis for the Sandwell group, indicating that metabolic factors other than insulin may be important once hepatic insulin resistance rises [30]. Portal blood NEFA may be one such key factor [31].

Hepatic insulin resistance is an important factor in the metabolic dysregulation associated with impaired glucose homeostasis. Given the established downregulation of IGFBP-1 production by hepatic portal insulin [32], IGFBP1 could be a useful marker for hepatic insulin resistance. The relation between IGFBP-1 and peripheral insulin concentration (which we have taken as proportional to hepatic portal insulin) differs between the two sites (Fig. 2a). A unit increase in insulin in Navsari Gujaratis was associated with a greater decrease in circulating IGFBP-1 than in Sandwell, implying greater hepatic insulin sensitivity in Navsari, although differences in renal clearance and hepatic extraction of insulin were not measured. The Navsari group also had a significantly higher circulating IGFBP-1 concentration. These findings taken together point to IGFBP-1 being a valid marker for hepatic insulin sensitivity, higher levels of circulating IGFBP-1 associating with greater hepatic insulin sensitivity. The fact that the circulating concentration of IGFBP-1 in Navsari was significantly higher than in Sandwell at any given HOMA$\mathrm{B}$ (that is, for any given level of pancreatic insulin output) raises the question of what else regulates IGFBP-1 production in the liver. Differences in nutritional intake between the groups may provide a clue to this.

NEFA concentrations in portal blood are known to have a major and direct influence on the hepatic response to insulin and thus by implication on IGFBP-1 secretion. Also, circulating fatty acids, both observationally and experimentally, seem closely involved in the pathogenesis of type 2 diabetes [31,33]. Depending on chain length, fatty acids also stimulate insulin secretion $[34,35]$, which may further aggravate hepatic insulin resistance [36]. The fall in NEFA after glucose challenge between the sites (Fig. 3a), 
was less pronounced in Sandwell than in Navsari in the context of a greater rise in Sandwell in insulin levels after glucose challenge (Fig. 3b). This is compatible with greater peripheral and hepatic insulin resistance in the Sandwell Gujaratis, as indicated by their lower IGFBP-1 levels.

Theoretically, the cross-site differences that we describe could be related to different sample handling in Navsari and Sandwell. However, identical protocols were adhered to at both sites with regard to sample handling, this being closely monitored by the principal investigators, as were transit arrangements and the condition of the samples on arrival. We did not measure circulating proinsulin concentration in this study, and accept that some between-site differences could be accounted for by differences in proinsulin secretion.

As previously reported [15, 37] we found a strong relationship between low IGFBP-1 levels and an adverse cardiovascular risk profile (Table 3 ). The relation was weaker in the Sandwell Gujaratis than in Navsari. The finding of a negative association between circulating IGF-I and fasting/2-h glucose (Tables 5 and 6 ) is intriguing in the light of our previous results showing that low circulating IGF-I was predictive of higher 2-h glucose at the 5-year follow-up [6]. Fasting blood glucose levels are mainly determined by the rate of endogenous glucose production [38]. Postprandial changes in glucose concentrations, however, are related to numerous factors, including glucose uptake by skeletal muscle and peripheral insulin sensitivity, as well as by the rate of endogenous glucose production $[38,39]$. Given the relative paucity of hepatic IGF-I receptors [40], our observation is consistent with IGF-I mainly influencing peripheral glucose uptake in the postprandial state, either directly or indirectly via its effects on the action of insulin to dispose of glucose. In this context, it is likely that the principal determinant of increased postprandial IGF-I bioavailability is IGFBP-1, owing to the rapid fall in IGFBP-1 following food intake [40, 41].

We found that both circulating IGF-I and IGFBP-3 correlate positively with BMI. IGFBP-3 is strongly associated with higher fasting and 2-h insulin. We speculate that this is a compensatory mechanism whereby circulating IGF-I and IGFBP-3 levels rise in order to increase IGF-I delivery to metabolically active tissues with increasing insulin resistance.

In summary, the differences in circulating IGFBP-1, IGFBP-3 and IGF-I between Gujarat and the UK appear to reflect changes in cardiovascular risk, BMI and dietary change that are related to migration. Our results provide important evidence for the effect of environmental factors in modulating the biological activity of the IGF system. This may have major implications for the development of worsening glucose tolerance and cardiovascular disease in these at-risk populations.

Acknowledgements The authors gratefully acknowledge the support of the British Heart Foundation for funding this study.

\section{References}

1. Mbanya JC, Cruickshank JK, Forrester T et al (1999) Standardised comparison of glucose tolerance in west African origin populations: rural/urban Cameroon, Jamaica \& Caribbean migrants to Britain. Diabetes Care 22:434-440

2. Balajaran R (1995) Ethnicity and variations in the nation's health. Health Trends 27:114-119

3. Shaukat N, de Bono DP, Cruickshank JK (1993) Clinical features, risk factors and referral delay in British patients of Indian and European origin with angina matched for age and extent of coronary atheroma. BMJ 307:717-718

4. Cruickshank JK, Cooper J, Burnett M et al (1991) Ethnic differences in fasting plasma C-peptide and insulin in relation to glucose tolerance and blood pressure. Lancet 338:842-847

5. McKeigue PM, Shah B, Marmot MG (1991) Relation of central obesity and insulin resistance with high diabetes prevalence and cardiovascular risk in South Asians. Lancet 337:382-386

6. Sandhu MS, Heald AH, Gibson JM et al (2002) Circulating concentrations of insulin-like growth factor-I and development of glucose intolerance: a prospective observational study. Lancet 359:1740-1745

7. Fath KA, Alexander RW, Delafontaine P (1993) Abdominal coarctation increases insulin-like growth factor I mRNA levels in rat aorta. Circ Res 72:271-277

8. Ververis JJ, Ku L, Delafontaine P (1993) Regulation of insulinlike growth factor I receptors on vascular smooth muscle cells by growth factors and phorbol esters. Circ Res 72:1285-1292

9. Delafontaine P (1995) Insulin-like growth factor I and its binding proteins in the cardiovascular system. Cardiovasc Res 30:825-834

10. Duerr RL, Huang S, Miraliakbar HR et al (1995) Insulin-like growth factor-I enhances ventricular hypertrophy and function during the onset of experimental heart failure. J Clin Invest 95:619-627

11. Juul A, Scheike T, Davidsen M, Gyllenborg J, Jorgensen T (2002) Low serum insulin-like growth factor I is associated with increased risk of ischaemic heart disease: a populationbased case-control study. Circulation 106:939-944

12. Li Q, Li B, Wang X et al (1997) Overexpression of insulin-like growth factor-I in mice protects from myocyte death after infarction, attenuating ventricular wall dilatation, wall stress and cardiac hypertrophy. J Clin Invest 100:1991-1999

13. Vasan RS, Sullivan LM, D'Agostino RB et al (2003) Serum insulin-like growth factor I and risk for heart failure in elderly individuals without a previous myocardial infarction: the Framingham Heart Study. Ann Intern Med 139:642-648

14. Lee PD, Giudice LC, Conover CA et al (1997) Insulin-like growth factor binding protein-1: recent findings and new directions. Proc Soc Exp Biol Med 216:319-357

15. Heald AH, Cruickshank JK, Riste LK et al (2001) Close relationship of fasting insulin-like growth factor binding protein-1 (IGFBP-1) with glucose tolerance and cardiovascular risk in 2 populations. Diabetologia 44:333-339

16. Cruickshank JK, Heald AH, Anderson S et al (2001) Epidemiology of the insulin-like growth factor system in three ethnic groups. Am J Epidemiol 154:504-513

17. Heald AH, Siddals KW, Fraser W et al (2002) Low circulating levels of insulin-like growth factor binding protein-1 (IGFBP1) are closely associated with the presence of macrovascular disease and hypertension in type 2 diabetes. Diabetes 51:26292636

18. Vaessen N, Heutink P, Janssen JA et al (2001) A polymorphism in the gene for IGF-I: functional properties and risk for type 2 diabetes and myocardial infarction. Diabetes 50:637-642

19. Hankinson SE, Willett WC, Colditz GA et al (1998) Circulating concentrations of insulin-like growth factor-I and risk of breast cancer. Lancet 351:1393-1396

20. Chan JM, Stampfer MJ, Giovannucci E et al (1998) Plasma insulin-like growth factor-I and prostate cancer risk: a prospective study. Science 279:563-566 
21. Chaturvedi N, McKeigue PM (1994) Methods for epidemiological surveys of ethnic minority groups. J Epidemiol Community Health 48:107-111

22. Alberti KGMM, Zimmet PZ, for the WHO Consultation (1998) Definition, diagnosis and classification of diabetes mellitus and its complications: Part I. Diagnosis and classification of diabetes mellitus. Provisional report of a WHO consultation. Diabet Med 15:539-553

23. Westwood M, Gibson JM, Davies AJ et al (1994) The phosphorylation pattern of insulin-like growth factor binding protein-1 in normal plasma is different from that in amniotic fluid and changes during pregnancy. J Clin Endocrinol Metab 79:1735-1741

24. Gordon C, Yates AP, Davies D (1985) Evidence for a direct action of exogenous insulin on the pancreatic islets of diabetic mice: islet response to insulin pre-incubation. Diabetologia 28:291-294

25. Matthews DR, Hosker JB, Rudenski AS et al (1985) Homeostasis model assessment: insulin resistance and beta cell function from fasting plasma glucose and insulin concentrations in man. Diabetologia 28:412-419

26. Ferrannini E, Mari A (1998) How to measure insulin sensitivity. J Hypertens 16:895-906

27. Silverman BW (1986) Density estimation for statistics and data analysis, monographs on statistics and applied probability. Chapman and Hall, London

28. Villafuerte BC, Zhang WN, Phillips LW (1996) Insulin and insulin-like growth factor-I regulate hepatic insulin-like growth factor binding protein-3 by different mechanisms. Mol Endocrinol 10:622-630

29. Underwood LE, Clemmons DR, Maes M et al (1986) Regulation of somatomedin-C/insulin-like growth factor I by nutrients. Horm Res 24:166-176

30. Kraegen EW, Clark PW, Jenkins AB et al (1991) Development of muscle insulin resistance after liver insulin resistance in high-fat-fed rats. Diabetes 40:1397-1403
31. Boden G (1997) Role of fatty acids in the pathogenesis of insulin resistance and NIDDM. Diabetes 46:3-10

32. Conover CA, Lee PDK, Kanaley JA et al (1992) Insulin regulation of insulin-like growth factor binding protein-1 in obese and non-obese humans. J Clin Endocrinol Metab 74: $1355-1360$

33. Charles MA, Eschewege E, Thibult N et al (1997) The role of non-esterified fatty acids in deterioration of glucose tolerance in Caucasian subjects: the Paris Prospective Study. Diabetologia 40:1101-1106

34. Stein DT, Stevenson BE, Chester MW et al (1997) The insulinotropic potency of fatty acids is influenced profoundly by their chain length and degree of saturation. J Clin Invest 100:398-403

35. Paolisso G, Gambardella A, Amato R et al (1995) Opposite effects of short- and long-term fatty acid infusion on insulin secretion in healthy subjects. Diabetologia 398:1295-1299

36. Maron DJ, Fair JM, Haskell WL (1991) Saturated fat intake and insulin resistance in men with coronary artery disease. The Stanford coronary risk intervention project. Circulation 84: 2020-2027

37. Mohamed-Ali V, Pinkney JH, Panahloo A et al (1999) Insulinlike growth factor binding protein in NIDDM. Clin Endocrinol $50: 221-228$

38. Bavenholm PN, Pigon J, Ostenson CG et al (2001) Insulin sensitivity of suppression of endogenous glucose production is the single most important determinant of glucose tolerance. Diabetes 50:1449-1454

39. Firth RG, Bell PM, Marsh HM et al (1986) Postprandial hyperglycaemia in patients with NIDDM: role of hepatic and extrahepatic tissues. J Clin Invest 77:1525-1532

40. Jones JI, Clemmons DR (1995) Insulin-like growth factors and their binding proteins: biological functions. Endocr Rev 16:334

41. Lee PD, Giudice LC, Conover CA et al (1997) Insulin-like growth factor binding protein-1: recent findings and new directions. Proc Soc Exp Biol Med 216:319-357 